\section{Flower and Fruit Development in Tepary Bean}

\author{
Kitren G. Weis ${ }^{1}$ and Barbara D. Webster ${ }^{2}$ \\ Department of Agronomy and Range Science, University of California, \\ Davis, CA 95616
}

Additional index words. Phaseolus acutifolius, abscission, abortion

Abstract. The drought-adapted, disease-resistant tepary bean (Phaseolus acutifolius A. Gray. var. acutifolius) is of great value as a potential gene donor of useful traits to the common bean (P. vulgaris L.). Analyses of flowering and fruiting patterns of tepary indicate that anthesis and abscission of reproductive structures within a raceme follow well-defined spatial and temporal patterns. Flowering occurs acropetally, and the probability of flowering decreases with distance from the most basal bud of the raceme. The probability of bud or pod abortion increases with distance from the basal bud, and the rate of abortion is highest in buds and pods proximal to the apex. Buds that never reach anthesis abort in the green-bud stage of development and aborting fruits cease development within the first $25 \%$ increase in pod length. In nonaborting fruits, the rate of seed abortion is $6 \%$. A marked increase in abscission of all buds and fruits at all raceme nodes occurs before cessation of flowering.
The tepary bean is of particular interest as a potential gene donor of desirable traits to commercial common bean cultivars. Unlike tepary beans, most common bean cultivars are ill-adapted to hot, arid environments (Pratt, 1983; Thomas et al., 1983). In addition, the drought-, heat-, and disease-resistant tepary has potential as an alternate leguminous crop in locales in which disease susceptibility and other cultural and production problems limit common bean yields. Tolerance of teparies to high temperatures and low water levels is well-documented (Thomas et al., 1983), and flowering response in relation to daylength has been established (Pratt and Erickson, 1982). However, morphological components of tepary flowering and fruiting behavior have not been examined. Teparies are known to be self-compatible, to have high pollen viability, and to pollinate effectively within the closed bud (Lord and Kohorn, 1986). They also exhibit embryo and fruit abortion, the causes of which are unknown.

Extensive studies of flowering or fruiting in relation to position within a raceme, cultural practices, and effects of endogenous growth regulators on reproductive development of Phaseolus vulgaris and Glycine max suggest that flower and fruit abortion occur as a result of critical physiological interactions; these may involve the entire plant and/ or the reproductive organs within an inflor-

Received for publication 28 Oct. 1988. We acknowledge with gratitude the assistance of Leslie Gray in data collection. We also thank Giles Waines and William C. Wells of the Univ. of California, Riverside, for tepary seed. The cost of publishing this paper was defrayed in part by the payment of page charges. Under postal regulations, this paper therefore must be hereby marked advertisement solely to indicate this fact.

'Postgraduate Researcher. Present address: Dept. of Pomology, Univ. of California, Davis, CA 95616

'Professor, to whom reprint requests should be addressed. escence (Tamas et al., 1979; Huff and Dybing, 1980; Binnie and Clifford, 1981; Mauk et al., 1987; Sage and Webster, 1987). Conversely, quantitative analyses of reproductive growth, development, and fruit abscission in racemes of $P$. vulgaris suggest that fruiting organs may abort as a result of nutritional competition within and among individual racemes (Adams, 1967). Whatever the cause, it is apparent that, although many large-seeded legumes flower profusely, seed and pod yields are significantly reduced by high rates of flower and fruit abscission.

This study examined spatial and temporal patterns of reproduction in the tepary bean. The research addressed the sequence of floral initiation and anthesis within racemes; critical periods of flower, pod, and seed abortion within racemes; and position of a reproductive organ in relation to its ultimate fate.

Methodology generally followed that of Sage and Webster (1987). Seeds of tepary bean, CIAT \#G40016, were planted in potting soil on 1 Jan. 1988 and grown in a greenhouse at the Univ. of California, Davis,

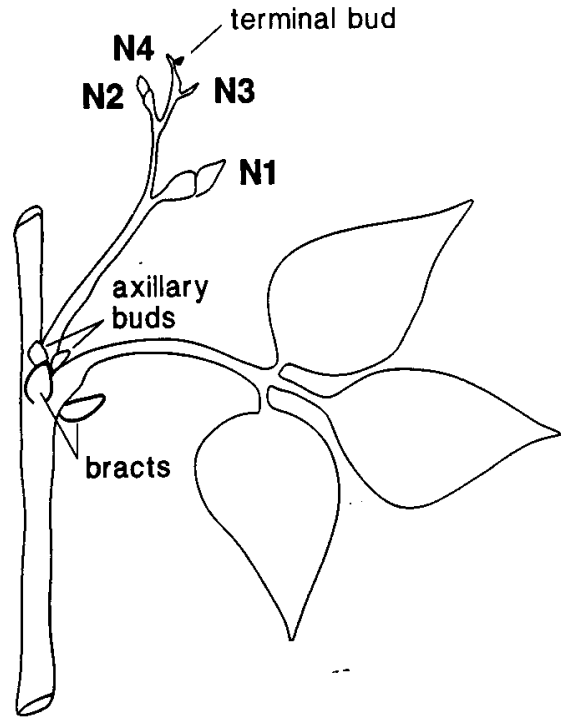

Fig. 1. Spatial array of reproductive organs within a raceme of Phaseolus acutifolius (N1, N2, N3,

at ambient temperature and sunlight. The 10 most vigorous plants selected for study were watered alternately with full-strength Hoagland's solution (Hoagland and Arnon, 1939) and distilled water. Nodes on the main stem were numbered successively, beginning with the cotyledonary node. Three axillary buds developed at each node beginning at nodes 13,14 , or 15 , although only one bud developed to form a raceme. Three racemes per plant were randomly selected from nodes 13 to 15 on 15 Mar. 1988, and their development was monitored daily for 2 weeks. Sequence of flowering, number of flowers per raceme, time of anethesis, and extent of abortion were recorded in relation to floral position within the raceme. Only one bud was present at any node on the raceme. Nodes at which reproductive structures (buds, flowers, and fruits) occurred were numbered, designating the most basal (proximal) as N1 (node one) and those developing acropetally as N2, N3, and N4. The terminal bud did not develop on any raceme and, thus, was not numbered. Day of anthesis of the first and $\mathrm{N} 4=$ nodes 1 to 4 , respectively).

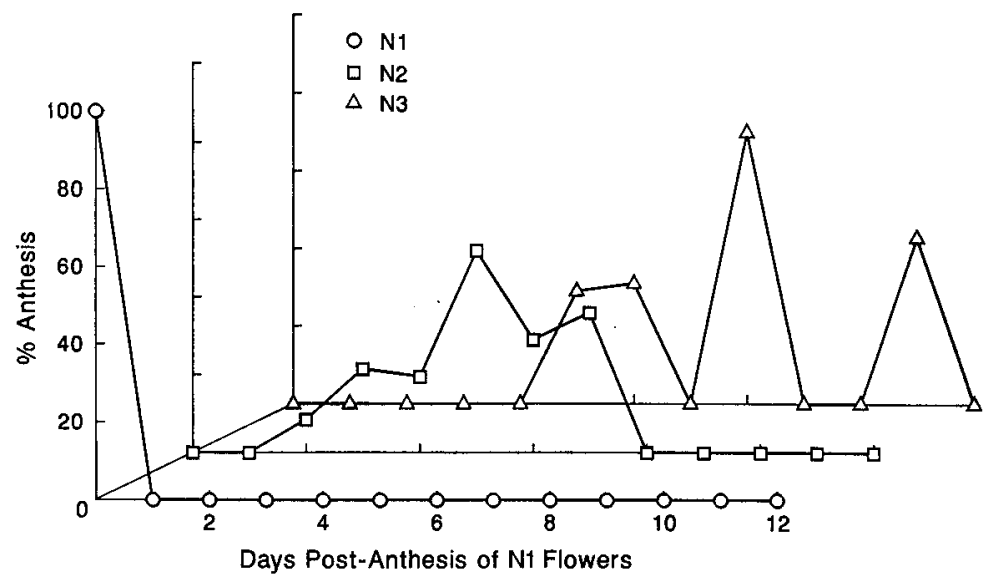

Fig. 2. Percent of anthesis of floral buds at nodes 1,2 , and $3(\mathrm{~N} 1, \mathrm{~N} 2, \mathrm{~N} 3)$ within 30 racemes from 10 plants on days 0 to 12 . Day 0 is the first day of anthesis within a raceme. 


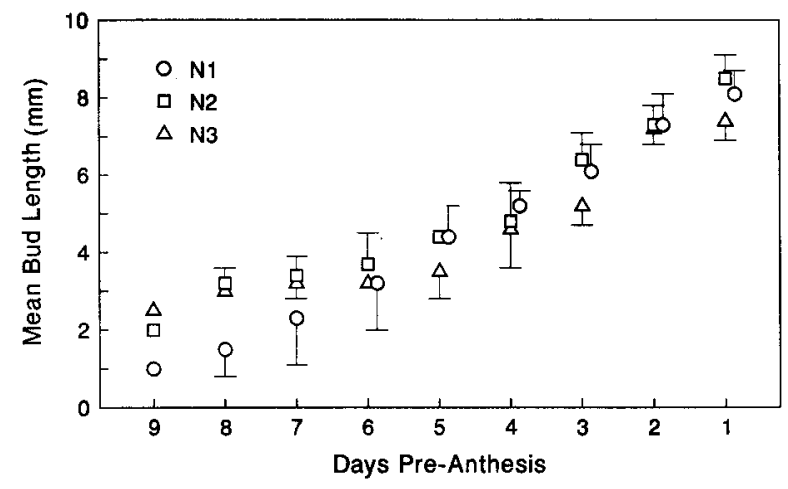

Fig. 3. Mean bud length of floral buds at nodes 1, 2, and $3(\mathrm{~N} 1, \mathrm{~N} 2, \mathrm{~N} 3)$ within 30 racemes from 10 plants before anthesis of each bud. Vertical bars represent SE of the mean.

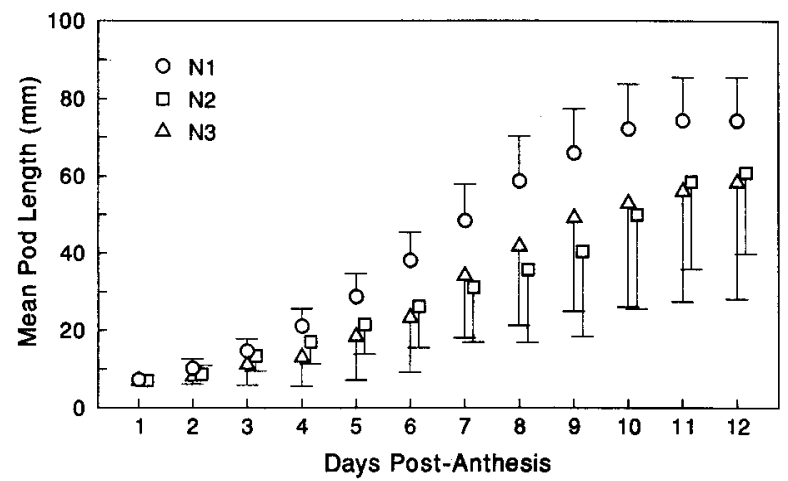

Fig. 4. Mean pod length over time of nonabscising fruits at nodes 1, 2, and 3 (N1, N2, N3) within 30 racemes from 10 plants. Vertical bars represent SE of the mean.

flower was considered day zero for the entire raceme. Lengths of buds and pods were recorded daily. Mature pods were removed and dissected to determine percent of seed abortion.

The simple raceme of the tepary is comprised of two to four nodes plus a terminal bud and is subtended by a trifoliolate leaf (Fig. 1). In addition, two axillary buds are positioned adjacent to the base of the peduncle; these did not develop under our growing conditions. Floral buds develop acropetally from N1 to N4, and the most basal bud (N1) is the first to flower.

In $30 \%$ of the racemes, only two floral buds were present; three or four buds appeared on $53 \%$ and $17 \%$, respectively, of the remaining racemes. In all racemes, buds at $\mathrm{N} 1$ reached anthesis $98 \%$ of the time. Buds at $\mathrm{N} 2, \mathrm{~N} 3$, and $\mathrm{N} 4$ flowered $73 \%, 38 \%$, and $0 \%$, respectively. There were several peaks of flowering for buds at N2 and N3 (Fig. 2). Flowering at $\mathrm{N} 2$ began at day 2 and was completed on day 8; flowering at $\mathrm{N} 3$ was delayed until day 5 and completed on day 12.

Buds that eventually reached anthesis elongated rapidly after reaching a length of 3 to $4 \mathrm{~mm}$, regardless of position within the raceme (Fig. 3). These buds opened when they reached 7.5 to $8.5 \mathrm{~mm}$. Abortive buds at $\mathrm{N} 1, \mathrm{~N} 2$, and $\mathrm{N} 3$ ceased to elongate at 2 to $3 \mathrm{~mm}$, became chlorotic, and eventually abscised. No buds at N4 developed beyond $1 \mathrm{~mm}$; they also abscised.
Frequency of pod abscission depended on position within the raceme. All fruits at N1 were retained on all racemes. Those at N2 and $\mathrm{N} 3$ abscised $23 \%$ and $57 \%$ of the time, respectively. The average length of pods at $\mathrm{N} 2$ at abscission was $11 \mathrm{~mm}$; that of pods at $\mathrm{N} 3$ was $6 \mathrm{~mm}$. Mean pod length of nonabscising pods at $\mathrm{N} 1$ exceeded those at $\mathrm{N} 2$ and N3 throughout the period of elongation (Fig. 4), suggesting a difference in rate of pod growth. On all mature fruits at all positions within the raceme, seed number per pod ranged from 4 to 6 , and $6 \%$ of the seeds of mature fruits aborted.

These phonological analyses of flowering and fruiting patterns in tepary demonstrate that the timing of anthesis, flower and fruit growth, and abortion of reproductive organs are positively correlated with the spatial arrangement of reproductive structures on the raceme axis. Consonant with results of analyses by Tamas et al. (1979) and Sage and Webster (1987) for P. vulgaris, the most basal reproductive organs of $P$. acutifoliuis develop more rapidly, flower first, and abort less frequently than those positioned more distally. In the tepary, buds that flower at successively later times (N2, N3, and N4) are progressively more arrested in development until buds at N1 have reached anthesis, and, furthermore, are highly likely to abort. Rates of floral abscission are highest at N3 and N4 and lower at N1 and N2. The low rate of abortion of pods at $\mathrm{N} 1$ and $\mathrm{N} 2$, as well as the very low percent of seed abor- tion, suggest that hybridizing tepary with various common bean cultivars that have high percentages of embryo, seed, and fruit abortion (Sage and Webster, 1987) could be beneficial in that less potentially abortive reproductive biomass might be expended.

Reproductive success of basal organs at the expense of those more distal is a common pattern in many crop plants and has been attributed, in part, to unequal allocation of nutrients among reproductive structures (Adams, 1967; Binnie and Clifford, 1981). Abortion among leguminous crop plants may result from nutrient deficiency in more distal organs if basal organs of a raceme can compete more successfully for limited resources (Tamas et al., 1979). Stronger sink strength in basal organs may be related to proximity to assimilates, as well as to their larger size (Cook and Evans, 1978). Hormonal interactions among reproductive organs of a raceme may also be significant in selective abortion (Tamas et al., 1979). This study does not address the possible causes of flower and fruit abortion in tepary bean; however, it does support the hypothesis of position-, age-, and/or time-specific abortion.

\section{Literature Cited}

Adams, M.W. 1967. Basis of yield component compensation in crop plants with special reference to the field bean, Phaseolus vulgaris. Crop Sci. 7:505-510.

Binnie, R.C. and P.E. Clifford. 1981. Flower and pod production in Phaseolus vulgaris. J. Agr. Sci. 97:397-402.

Cook, M.G. and L.T. Evans. 1978. Effect of relative size and distance of competing sinks on the distribution of photosynthetic assimilation in wheat. Austral. J. Plant Physiol. 5:495-509.

Hoagland, D.R. and D.I. Amen. 1939. The water culture method for growing plants without soil. Calif. Agr. Expt. Sta. Circ. 347.

Huff, A. and C.D. Dybing. 1980. Factors affecting shedding of flowers in soybean [Glycine max (L.) Merrill]. J. Expt. Bet. 31:751-762.

Lord, E.M. and L.U. Kohorn. 1986. Gynoecial development, pollination, and the path of pollen tube growth in the tepary bean, Phaseolus acutifolius. Amer. J. Bet. 73:70-78.

Mauk, C. S., P.J. Breen, and H.J. Mack. 1987. Flower and pod abscission in snap bean as influenced by inflorescence position, raceme node, irrigation and plant density. Can. J. Plant Sci. 67:1193-1202.

Pratt, R.C. 1983. Gene transfer between tepary and common beans. Desert Plants $5: 57-63$.

Pratt, R.C. and H.T. Erickson. 1982. Flowering response of Phaseolus acutifolius Gray and subspecies to photoperiod. Annu. Rpt. Bean Imp. Coop. 25:1-2.

Sage, T.L. and B.D. Webster. 1987. Flowering and fruiting patterns of Phaseolus vulgaris L. Bet. Gaz. 148:35-41.

Tamas, I. A., D.H. Wallace, P.M. Ludford, and J. Ozbun. 1979. Effect of older fruits on abortion and abscisic acid concentration of younger fruits in Phaseolus vulgaris L. Plant Physiol. 64:620-622.

Thomas, C. V., R.M. Manshardt, and J.G. Waines. 1983. Teparies as a source of useful traits for improving common beans. Desert Plants 5:4348. 